\title{
MÉTODOS MOLECULARES NA VIGILÂNCIA EPIDEMIOLÓGICA DE DOENÇAS INFECCIOSAS
}

\author{
REGUA-MANGIA, Adriana Hamond \\ Mestre em Ciências Biológicas pelo Instituto de Biofísica da Universidade Federal do Rio \\ de Janeiro, Doutora em Microbiologia pelo Instituto de Microbiologia da Universidade \\ Federal do Rio de Janeiro, Pesquisadora em Saúde Pública da Escola Nacional de Saúde \\ Pública Sergio Arouca (ENSP/Fiocruz), atuando na pesquisa laboratorial de patógenos \\ bacterianos e no ensino, em nível de pós-graduação stricto e lato sensu. E-mail: \\ regua@ensp.fiocruz.br
}

\begin{abstract}
RESUMO
A tipagem molecular de microrganismos patogênicos tem contribuído enormemente para a eficácia de programas de vigilância epidemiológica em todo o mundo, subsidiando estratégias de prevenção e controle de doenças infecciosas. O papel principal desses sistemas de tipagem consiste em acessar a inter-relação genética de isolados microbianos. A acurácia dos diferentes métodos permite assim definir a fonte e rotas de infecção, esclarecer a ocorrência de surtos, caracterizar clones epidêmicos, identificar a circulação de linhagens virulentas e avaliar a efetividade de medidas de controle. A partir da década de 70, foram desenvolvidas técnicas laboratoriais para a análise de ácidos nucléicos caracterizando um novo paradigma para a Saúde Pública. Atualmente existem inúmeras técnicas, com vantagens e limitações conforme critérios internacionais, as quais as tornam aplicáveis para alguns estudos e restritos a outros. A escolha do método vai depender da questão epidemiológica a ser respondida e da disponibilidade de recursos do laboratório. Essas tecnologias requerem capacitação técnico-operacional, adequação física para sua instalação e a aquisição de programas computacionais específicos destinados a captura da imagem, a análise do DNA e a guarda de resultados. Esse artigo apresenta os fundamentos e aplicabilidade dos métodos moleculares de tipagem mais empregados no estudo epidemiológico de doenças infecciosas.
\end{abstract}

PALAVRAS-CHAVE: epidemiologia molecular, laboratório, doença infecciosa, vigilância.

\section{MOLECULAR METHODS IN EPIDEMIOLOGICAL SURVEILLANCE OF INFECTIOUS DISEASES}

\begin{abstract}
Molecular typing of pathogenic microorganisms has greatly contributed to the effectiveness of epidemiological surveillance programs worldwide, supporting strategies for prevention and control of infectious diseases. The main role of typing systems is to assess the genetic relationship between microbial isolates. The accuracy of different methods has determined the source and routes of infections, confirmed outbreaks, characterized epidemic clones, recognized virulent strains and evaluated the effectiveness of control measures. From the 1970s, laboratory techniques for the analysis of nucleic acids sequences established a new paradigm for public health purposes. Currently, a broad range of techniques is available, presenting advantages and limitations based on international criteria, which make them applicable to some studies and restricted to others.
\end{abstract}


The decision whether to use one or another choice of method will need to consider the suitability to a specific epidemiological question and laboratory resources. These technologies require technical and operational training, appropriate areas for their installation and the acquisition of specific computer software for the image capture, comparative DNA analysis and data storage. This article describes the fundamentals and applicability of the most used molecular typing systems in the epidemiological studies of infectious diseases.

KEY WORDS: MOLECULAR EPIDEMIOLOGY, LABORATORY, INFECTIOUS DISEASE, SURVEILLANCE.

\section{MÉTODOS MOLECULARES NA VIGILÂNCIA EPIDEMIOLÓGICA DE DOENÇAS INFECCIOSAS}

\section{INTRODUÇÃO}

As doenças infecciosas têm expressivo impacto na morbidade em todo o mundo sendo responsáveis por dezenas de milhões de mortes por ano, principalmente, aquelas que não dispõem de mecanismos eficazes de prevenção e controle. Nos países em desenvolvimento, essas questões representam constantes desafios e refletem limitações de natureza diversa. As ações da vigilância em saúde buscam de forma integrada e intersetorial o desenvolvimento de estratégias, visando responder com efetividade e eficácia os problemas de prevenção e controle de doenças infecciosas e outros agravos à saúde (BARRETO et al., 2011).

Em todo esse processo, o laboratório assume um papel crucial no diagnóstico do agente infeccioso e participa ativamente nas ações de vigilância epidemiológica. Neste contexto destaca-se a Epidemiologia Molecular, que é o ramo da ciência médica que utiliza tecnologias da biologia molecular no suporte a investigações epidemiológicas. Essas ferramentas laboratoriais têm importante aplicabilidade no monitoramento de espécies e na detecção de linhagens ou variantes de populações microbianas (BELKUM et al., 2001; BLANC, 2004; GILBERT, 2002; GWINN, BOWEN, KHOURY, 2006). Os resultados dessas análises associados com a identificação de outros marcadores biológicos como as propriedades específicas de virulência, têm permitido detectar a circulação de clones e delinear o padrão epidemiológico de doenças infecciosas (HASNAIN, 2003; Li, RAOULT, FOURNIER, 2009).

O laboratório no apoio às vigilâncias pode atuar no diagnóstico e na tipagem de microrganismos. O desenvolvimento de técnicas de biologia molecular, nestes últimos 20 anos, tem conferido, cada vez mais, maior sensibilidade e especificidade aos testes e favorecido a revisão e a incorporação de conceitos, visando atender às tecnologias emergentes (HASNAIN, 2003; MILLAR, XU, MOORE, 2007). Desde a descoberta, na década de 80, da reação em cadeia da polimerase (em inglês, Polymerase Chain Reaction PCR), uma enorme variedade de métodos foram introduzidos na pesquisa e na rotina clínica microbiológica. Atualmente, a biologia molecular oferece um grande repertório de métodos com aplicações específicas e que requerem para a análise e interpretação dos seus resultados, o conhecimento de conceitos e fundamentos técnicos (BLANC, 2004; GILBERT, 2002). Muitas técnicas moleculares foram desenvolvidas para fins 
diagnósticos, enquanto os sistemas de tipagem são empregados visando a detecção de variantes ou linhagens de microrganismos dentro da mesma espécie microbiana (BLANC, 2004; SINTCHENKO, GALLEGO, 2009). Essas metodologias de tipagem genética têm um papel relevante no rastreamento de linhagens patogênicas, na identificação de fontes de infecção, no monitoramento da resistência a antimicrobianos, na detecção da emergência e circulação de clones epidêmicos (RANJBAR e al., 2014; SINTCHENKO, IREDELL, GILBERT, 2007). A implementação de métodos empregados na análise do polimorfismo de ácidos nucléicos abriu novas possibilidades para os campos da classificação, identificação e diagnóstico. Os conceitos e a aplicabilidade dessas importantes ferramentas moleculares que se baseiam nas características genéticas de agentes infecciosos são apresentados a seguir.

\section{SISTEMAS, MÉTODOS OU TECNOLOGIAS DE TIPAGEM}

Compreender o perfil e a distribuição de microrganismos patogênicos e as suas interrelações genéticas são cruciais para a determinação do perfil bioepidemiológico do agente infeccioso e para o auxílio do desenho racional de ações de controle de doenças (LI, 2009). A inter-relação genética de populações microbianas é investigada por metodologias laboratoriais conhecidas como sistemas moleculares de tipagem (BELKUM, 2001; BLANC, 2004; SINTCHENKO, IREDELL, GILBERT, 2007). A tipagem molecular tem especial importância no estudo de surtos/epidemias, tanto nas infecções de origem comunitária como entre as nosocomiais mas também são utilizadas no monitoramento de infecções endêmicas (LI, RAOULT, FOURNIER, 2009; MacCANNELL, 2013). O papel da tipagem molecular consiste em investigar a relação de identidade genética entre microrganismos epidemiologicamente relacionados.

A tipagem baseada na análise do polimorfismo genético foi introduzida com sucesso, na década de 90, e inicialmente era realizada por métodos muito laboriosos e custosos. A padronização de metodologias, sensibilidade, especificidade e objetividade são importantes exigências técnicas que devem ser levadas em consideração para o sucesso de um esquema de tipagem (BLANC, 2004; LI, RAOULT, FOURNIER, 2009; MacCANNELL, 2013; RANJBAR et al., 2014; SINTCHENKO, IREDELL, GILBERT, 2007). Essas metodologias são internacionalmente avaliadas com base nos seguintes critérios técnicos: i) potencial de tipagem ou tipabilidade, que se refere a capacidade da técnica em não fornecer resultados inequívocos para cada isolado (tipo). Isolados não tipáveis são aqueles que apresentam resultados nulos ou ambíguos e embora tais resultados sejam mais comuns com métodos fenotípicos, podem também ocorrer com métodos genotípicos; ii) reprodutibilidade, que se refere a capacidade do método em fornecer o mesmo resultado após repetidos testes. Baixa reprodutibilidade pode refletir problemas no processamento técnico ou na variação biológica, possivelmente decorrente de passagens sucessivas in vivo ou in vitro do agente microbiano em teste; iii) estabilidade, que se refere a capacidade do método em manter constante o reconhecimento de marcadores estáveis, presentes em isolados idênticos ou estreitamente relacionados; iv) concordância epidemiológica, que consiste do método em agrupar corretamente os isolados epidemiologicamente correlacionados e; v) poder discriminatório, refere-se à capacidade do método em discriminar ou diferenciar microrganismos epidemiologicamente relacionados dos não relacionados. Custo e acessibilidade também são critérios considerados na avaliação dos sistemas de tipagem. As metodologias de tipagem atualmente utilizadas não atendem a todos os critérios de avaliação e, portanto, a tipagem ideal requer a utilização de mais de 
um sistema (RANJBAR et al, 2014). A escolha do método deverá satisfazer o propósito da análise e as condições experimentais disponíveis, requerendo o conhecimento de características microbiológicas e do contexto epidemiológico. Parâmetros como a ocorrência de eventos genéticos e a natureza das sequências genéticas envolvidas são fundamentais para a análise e a interpretação dos resultados (HASNAIN, 2009; MacCANNELL, 2013; RANJBAR et al., 2014).

\section{Métodos genéticos ou genotípicos de tipagem}

As técnicas genotípicas têm recebido atenção crescente, nos últimos anos, como ferramentas para o diagnóstico e para a análise de inter-relação das subpopulações microbianas. Por meio da genotipagem, o estudo e o controle de infecções objetivam investigar se microrganismos isolados em um dado evento epidemiológico são relacionados (MacCANNELL, 2013; RANJBAR et al., 2014).

O emprego da tipagem em decisões de controle de infecção é baseado em várias hipóteses: (i) isolados associados ao surto são descendentes de uma única célula precursora (comum) e, portanto, constituem um clone, (ii) tais isolados terão o mesmo genótipo, e (iii) isolados epidemiologicamente não relacionados terão genótipos diferentes. Existem algumas exceções a estes pressupostos: isolados epidemiologicamente relacionados podem ter genótipos semelhantes ou indistinguíveis se houver diversidade genética limitada dentro de uma espécie/subtipo, ou se o método de genotipagem escolhido não é o ideal para distinguir entre os isolados não-clonais. Em outros casos, eventos genéticos como mutação e aquisição de plasmídeos podem ocorrer durante o surto, podendo comprometer a análise e a interpretação dos resultados.

Os métodos genéticos de tipagem podem ser classificados em categorias principais como: técnicas que geram padrão de bandas, técnicas de sequenciamento, técnicas baseadas em ensaios de hibridização e curvas de melting (LUKINMAA, et al., 2004; MacCANNELL, 2013; RANJBAR et al., 2014; SINTCHENKO, 2009; SWAMINATHAN, et al, 2001; TAUXE, 2006).

\section{Técnicas que geram padrões de bandas (fragmentos) de DNA:}

Os métodos que geram padrões de bandas de DNA (polimorfismo) discriminam com base nas diferenças dos tamanhos fragmentos (bandas). Bandas de DNA (fragmentos) podem ser provenientes da digestão do DNA com enzimas de restrição (ERs), de ensaios de amplificação, ou pela combinação de ambos (LI, RAOULT, FOURNIER, 2009; LUKINMAA et al., 2004; MacCANNELL, 2013; RANJBAR et al., 2014).

\section{Restrição enzimática}

As ERs reconhecem a sequência genética alvo (sítio de reconhecimento) e corta de forma precisa (sítio de clivagem) a molécula do DNA, tornando a restrição enzimática um recurso eficaz em análises genéticas. 
Polimorfismo genético obtido após ação de ER (Restriction Fragment Length Polymorphism, RFLP)

O RFLP é o nome dado a todo perfil genético obtido após a ação de uma enzima de restrição e foi um dos primeiros recursos utilizados para a detecção de polimorfismos na sequência do DNA. Como o próprio nome sugere, o padrão RFLP revela o tamanho dos fragmentos de restrição após separação em corrida eletroforética. O procedimento geral inicia-se com a digestão do DNA com ERs que reconhecem sequências genéticas (sítios) no genoma, produzindo assim, após a ação enzimática, centenas de fragmentos os quais, dificilmente são bem separados (resolvidos) na eletroforese convencional em gel de agarose. Por isso, é muito comum essa metodologia ser combinada a outras técnicas como Southern blotting, que utiliza sondas marcadas para a identificação de alvos genéticos específicos. Os padrões de restrição obtidos podem ser usados para fazer uma análise comparativa entre os isolados. A técnica de RFLP pode ser usada para investigar o polimorfismo genético de regiões específicas do DNA ou para a análise do genoma total (LI, RAOULT, FOURNIER, 2009; LUKINMAA et al., 2004; RANJBAR et al., 2014).

A Ribotipagem é uma técnica de RFLP e utiliza uma sonda complementar à região do DNA codificadora do RNAr. Operons RNAr constituem famílias de genes altamente conservados ladeados por sequências variáveis. Variações no número e no tamanho dessas sequências determinam os diferentes padrões de bandeamento ou ribotipos com base na marcação a partir destas sondas específicas para os domínios conservados. Uma vantagem de ribotipagem é que a técnica permite a análise do DNA sem conhecimento prévio da sequência genômica pois os operons do RNAr são universais. O RFLP requer grandes quantidades de DNA genômico de alta qualidade, o que pode limitar a sua aplicação em muitos casos. A técnica consome tempo, é laboriosa, especialmente quando combinada com a técnica de Southern blotting e envolve sistemas de detecção que utilizam ou radioisótopos ou bioquímica complexa.

\section{Eletroforese em gel de campo pulsado (Pulsed Field Gel Electrophoresis, PFGE)}

O PFGE é uma técnica de macrorestrição que utiliza um sistema de eletroforese com campos elétricos alternados dispostos em diferentes ângulos. Para o PFGE são utilizadas ERs que reconhecem sequências genéticas (sítios) pouco frequentes no genoma, gerando, dessa forma, fragmentos de DNA na faixa de $10 \mathrm{~Kb}-10 \mathrm{Mb}$. O PFGE é considerada como uma técnica "padrão ouro" para a subtipagem de muitos grupos bacterianos (LI, RAOULT, FOURNIER, 2009; LUKINMAA et al., 2004; RANJBAR et al., 2014). Para a técnica de PFGE os protocolos experimentais devem seguir procedimento técnico validado de modo a permitir a comparação com padrões internacionais de bandeamento. $\mathrm{O}$ banco referência internacional para dados do PFGE é o PulseNet que acumula informações de relevantes patógenos bacterianos (SWAMINATHAN et al., 2001).

A análise e a interpretação dos resultados do PFGE devem seguir critérios definidos internacionalmente que consideram a ocorrência de eventos genéticos. Segundo esses critérios de interpretação, diferentes isolados com o mesmo padrão de bandeamento são considerados a mesma cepa. Para perfis que diferem de uma a três bandas, os isolados são considerados estreitamente associados. Isolados que diferem de quatro a seis bandas, sugerem a ocorrência de eventos genéticos independentes e são considerados como possivelmente relacionados. Isolados com mais de seis bandas de diferença refletem a ocorrência de três ou mais eventos genéticos e são classificados como 
epidemiologicamente não relacionados. A análise de perfis eletroforéticos mais complexos requerem a utilização de programas computacionais para a análise e interpretação da estrutura genética e da inter-relação entre os microrganismos (LUKINMAA et al., 2004; SINTCHENKO, GALLEGO, 2009). Embora amplamente utilizado e reconhecido como uma técnica de tipagem de referência, o PFGE é tecnicamente laborioso, requer infraestrutura apropriada, quantidade e alta qualidade de DNA. Todas as etapas envolvidas nos ensaios experimentais e na corrida eletroforética, incluindo ajustes de pulsos, voltagem, temperatura, composição do tampão, concentração e quantidade da agarose, devem seguir o protocolo de referência, uma vez que alterações indesejáveis podem inviabilizar comparações com padrões de bandeamento.

\section{Amplificação do DNA}

Amplificação randômica do DNA polimórfico (Random Amplification of Polymorphic $D N A$, RAPD-PCR)

O RAPD-PCR é uma variação da reação de PCR destinada à amplificação aleatória de regiões genômicas utilizando iniciadores arbitrários. A reação normalmente utiliza primers (iniciadores) únicos e pequenos (geralmente com 10 bases) combinados e ocorre em condições de baixa estringência. Nessas condições de reação, o RAPD-PCR permite a amplificação de múltiplas regiões do DNA genômico, o que gera fragmentos de diferentes tamanhos. Ao contrário da técnica de PCR que é destinada à amplificação de regiões específicas do DNA, o RAPD-PCR não exige conhecimento prévio da sequência genética alvo. $\mathrm{O}$ número de fragmentos gerados dependerá do número de sítios de ligação/associação do iniciador com a sequência alvo (LI, RAOULT, FOURNIER, 2009; LUKINMAA et al., 2004; RANJBAR et al., 2014; TAUXE, 2006).

A técnica do RAPD-PCR é relativamente de baixo custo, rápida e de fácil execução. Em condições experimentais padronizadas, o método é reprodutível e com poder discriminatório comparável a outros sistemas clássicos de tipagem. Por ser uma metodologia que ocorre em condições de baixa estringência, a técnica é muito sensível e vários fatores podem influenciar os produtos de reação como: mudança na sequência dos iniciadores, ajustes nas temperaturas de reação, alterações no protocolo experimental relacionadas ao DNA em teste (quantidade/qualidade), aos reagentes químicos envolvidos (DNA polimerase, dNTP, cloreto de magnésio, tampões, etc) e aos parâmetros de reação (equipamentos). Assim sendo, a otimização das etapas envolvidas em todo protocolo de reação e na análise devem ser rigorosamente cumpridas.

Amplificação do DNA a partir de sequências repetitivas (Repetitive sequencing-based $P C R$, rep-PCR)

O rep-PCR é uma variação da reação de PCR que ocorre a partir de elementos ou sequências repetitivas no DNA, naturalmente dispersas e presentes em múltiplas cópias em genomas bacterianos (LI, RAOULT, FOURNIER, 2009; LUKINMAA et al., 2004; RANJBAR et al., 2014; TAUXE, 2006). Diferentemente do RAPD-PCR, o rep-PCR, utiliza iniciadores específicos complementares a essas regiões repetitivas e a partir delas são amplificados os fragmentos de DNA. Como é uma reação específica, os testes ocorrem sob condições de alta estringência (temperatura alta de anelamento). Sequências repetitivas são comumente utilizadas na tipagem e na diferenciação de populações bacterianas como 
as sequências REP, ERIC e BOX. As genotipagens realizadas a partir destas sequências são denominadas de REP-PCR, ERIC-PCR e BOX-PCR, respectivamente. Para a detecção de fragmentos de DNA, a partir das sequências repetitivas, a eletroforese é realizada em sistema convencional e em gel de agarose. A otimização das condições de corrida podem influenciar a resolução dos fragmentos de DNA amplificados com até 1000 pb.

O rep-PCR é de baixo custo, reprodutível, rápido e pode ser um método muito informativo para a tipagem de populações bacterianas diversas. Contudo, também requer cuidados da mesma forma que os demais protocolos baseados em reações de PCR como o potencial de contaminação, presença de artefatos e a necessidade de múltiplos controles.

Análise de sequências repetitivas do DNA (Multiple-locus variable number tandem repeat analysis, MLVA)

Sequências VNTR são dispersas no genoma de células bacterianas e variam em número de cópias. Essas sequências correspondem, portanto, a importantes alvos de detecção do polimorfismo genético de populações bacterianas e o número de repetições desses loci pode variar drasticamente entre linhagens dentro de uma determinada espécie. O MLVA é, assim, um método baseado no polimorfismo dos loci VNTR. Para cada locus VNTR, o número de repetições pode ser determinado pela reação de PCR, usando iniciadores complementares direcionados para essas sequências. O tamanho dos fragmentos varia de acordo com o número e o tamanho dessas unidades repetidas gerando um padrão de bandas (fragmentos). O MLVA é um método rápido, de fácil execução, de baixo custo, reprodutível e a genotipagem é de alta resolução (LI, RAOULT, FOURNIER, 2009; LUKINMAA et al., 2004; RANJBAR et al., 2014; TAUXE, 2006).

\section{Eletroforese em gel desnaturante (Denaturing gel electrophoresis, DGE)}

$\mathrm{Na}$ metodologia de DGE, os produtos do PCR são separados por eletroforese em poliacrilamida sob influência de um gradiente crescente de agente desnaturante. Nessas condições de corrida, a molécula de DNA de fita dupla (produto do PCR) avança, e se separa (dissocia), formando fita simples de DNA, à medida que encontra uma concentração de agente desnaturante capaz de separar seus domínios genéticos. Assim, quando moléculas de DNA apresentam diferenças pontuais em suas sequências, ou seja, diferentes domínios genéticos, estas apresentarão distintos padrões de dissociação e consequentemente, de migração (polimorfismo). Esse gradiente desnaturante pode ser obtido pela incorporação de agentes químicos no gel de eletroforese (DGGE) ou pelo calor, criando um gradiente de temperatura (TGGE). É um método laborioso e requer equipamento específico de eletroforese (LI, RAOULT, FOURNIER, 2009; LUKINMAA et al., 2004; RANJBAR et al., 2014; TAUXE, 2006).

Análise do polimorfismo genético de produtos de amplificação do DNA seguida de reação enzimática (PCR-RFLP)

A técnica de PCR-RFLP é um método de tipagem que consiste em submeter um produto de PCR à ação de ER (enzima de restrição). Esse ensaio tem por objetivo detectar variações nas sequências genéticas. Quando as sequências em análise apresentarem sítios de reconhecimento para as enzimas de restrição (ERs) empregadas, ocorrerá a clivagem da molécula, gerando fragmentos que serão separados e visualizados em gel de eletroforese 
convencional após coloração, sem a necessidade de complementar com ensaios de hibridização. O ensaio poderá ser mais informativo com o emprego de enzimas de restrição adicionais. O polimorfismo detectado poderá ser utilizado para análises comparativas entre sequências de diferentes microrganismos. A técnica de PCR-RFLP é uma metodologia simples, rápida, e não radioativa para detecção do polimorfismo do DNA (LI, RAOULT, MacCANNELL, 2013; LUKINMAA et al., 2004; FOURNIER, 2009; RANJBAR et al., 2014; TAUXE, 2006).

Análise do polimorfismo genético de produtos de restrição enzimática seguida de ensaios de amplificação (Amplified fragment length polymorphism, AFLP)

A técnica de AFLP combina a precisão do ensaio de ER com a especificidade do PCR, tornando o método altamente sensível para a detecção do polimorfismo do DNA. Para a análise de AFLP, a digestão do DNA genômico é feita, geralmente, empregando-se duas ERs seguida de uma etapa de ligação com adaptadores específicos para as enzimas utilizadas. Após esse procedimento, segue-se a uma etapa de amplificação seletiva com base nas sequências dos adaptadores. Os produtos obtidos pelo AFLP normalmente são muito complexos (50-100 fragmentos) e requerem software para a análise dos perfis eletroforéticos gerados. Maior discriminação pode ser obtida, empregando-se ERs adicionais. $\mathrm{O}$ método poderá ser otimizado, empregando marcadores fluorescentes para a detecção simultânea de fragmentos específicos. Os perfis obtidos permitem a comparação entre genomas de microrganismos diversos. O AFLP tem sido descrito como sendo tão discriminatório como PFGE, RAPD e RFLP para genoma total, mas requer equipamento automatizado necessário para a análise dos muitos fragmentos envolvidos (LI, RAOULT, FOURNIER, 2009; LUKINMAA et al., 2004; RANJBAR et al., 2014; TAUXE, 2006).

\section{Técnica de sequenciamento do DNA:}

A genotipagem a partir do sequenciamento consiste na caracterização definitiva do DNA e informa a sequência de nucleotídeos que compõem o fragmento em análise. A molécula do DNA é constituída por uma sequência de nucleotídeos responsável pela informação genética original de um dado organismo e pode ser usada diretamente para a diferenciação e análise filogenética. A vantagem mais significativa da técnica de sequenciamento do DNA sobre os demais métodos é a sua elevada precisão. Por se tratar de uma caracterização definitiva, com informação única, sem ambiguidades, o sequenciamento pode ser utilizado para análises comparativas entre diferentes laboratórios quando essas são depositadas em bancos de dados. O Gene-Bank é o maior banco de dados de sequências de DNA, contendo informações genéticas sobre a grande maioria dos agentes microbianos. O sequenciamento do DNA tem contribuído significativamente para muitos aspectos da microbiologia, detectando a ocorrência de eventos genéticos pontuais (mutação, deleção, inserção, substituição) ou envolvendo maiores regiões do genoma. A técnica do sequenciamento requer uma infraestrutura laboratorial específica, capacitação técnica, além de programas específicos para a análise dos resultados. Serviços de sequenciamentos de DNA são oferecidos por plataformas tecnológicas em muitos institutos de pesquisa (LI, RAOULT, MacCANNELL, 2013; LUKINMAA et al., 2004; FOURNIER, 2009; RANJBAR et al., 2014; TAUXE, 2006). 


\section{Técnicas baseadas em ensaios de hibridização do DNA:}

Os métodos baseados em ensaios de hibridização são atualmente referidos como macrodisposições (macroarrays) ou microdisposições (microarrays). Nesses ensaios, a discriminação é feita observando-se o padrão de hibridização com sondas marcadas que se ligam especificamente ao seu alvo genético no genoma.

A hibridização do DNA é amplamente utilizada para a detecção de sequências genéticas específicas (alvos). Dois elementos principais estão envolvidos na reação de hibridização: as sondas e os alvos genéticos. As sondas são fragmentos de DNA de sequência conhecida, enquanto que os alvos são sequências específicas presentes nos ácidos nucléicos a serem investigados, cuja identidade e abundância serão reveladas por testes de hibridização, empregando sondas marcadas complementares às sequências alvo. Atualmente, existem metodologias que empregam ensaios de hibridização que permitem a análise simultânea de uma grande quantidade de alvos genéticos. As microdisposições e as macrodisposições são metodologias rápidas, específicas e podem requerer programas e equipamentos especializados. Os ensaios de hibridização podem ser acoplados a ensaios de restrição dependendo do objetivo da análise (LI, RAOULT, MacCANNELL, 2013; LUKINMAA et al., 2004; FOURNIER, 2009; RANJBAR et al., 2014; TAUXE, 2006).

\section{Técnica baseada em curvas de melting:}

Análise de dissociação do DNA em alta resolução (High-resolution melting analysis, HRM analysis)

Assim como o DGE, o HRM também tem por objetivo discriminar produtos específicos do PCR através da temperatura de dissociação da fita dupla. O HRM usa o PCR em tempo real e faz análise da curva de dissociação. Da mesma forma como explorado pelo DGE, sequências distintas apresentam domínios genéticos distintos e requerem temperaturas diferenciadas para a sua dissociação. O padrão de dissociação de uma sequência dependerá de sua característica genética como teor de GC e tamanho do fragmento em análise. $\mathrm{O}$ HRM não é um método que gera padrões de bandas, mas é baseado em reações de amplificação e é extremamente sensível, detectando variações genéticas ao longo das sequências em análise. O HRM é um método muito sensível, mas utiliza um sistema altamente sofisticado para a reação e análise de seus resultados (LI, RAOULT, MacCANNELL, 2013; LUKINMAA et al., 2004; RANJBAR et al., 2014; TAUXE, 2006; SINTCHENKO, GALLEGO, 2009).

\section{ESCOLHA DO MÉTODO APROPRIADO DE (GENO)TIPAGEM}

O método de tipagem ideal deve ser aplicável a todos os isolados (validade), ter a capacidade de diferenciar isolados epidemiologicamente não relacionados (poder discriminatório), oferecer o mesmo resultado a partir de ensaios realizados intra e interlaboratorial (reprodutibilidade), apresentar rapidez, eficiência e facilidade de execução e interpretação (GWINN, BOWEN, KHOURY, 2006; HASNAIN, 2003; RANJBAR et al., 2014; TAUXE, 2006). Contudo, nenhum dos vários métodos de (geno)tipagem atualmente disponíveis atende a todos os critérios e ainda apresentam vantagens e desvantagens. Para estudos de vigilância de surtos/epidemias locais, marcadores genéticos que evoluem 
rapidamente devem ser usados como alvos de investigação, enquanto para estudos epidemiológicos a longo prazo, recomenda-se a análise de alvos genéticos conservados. Portanto, o conhecimento da sequência alvo a ser investigada é de extrema relevância tanto para a escolha do método como para a finalidade do ensaio. O poder discriminatório é considerado um dos critérios mais importantes para a seleção de um método genético, uma vez que a diferenciação entre isolados é o principal propósito da análise (MacCANNELL, 2013; RANJBAR et al., 2014). Populações microbianas podem parecer idênticas quando submetidas à análises fenotípicas ou genotípicas de baixa resolução; entretanto, podem ser diferenciadas quando submetidas a ensaios de genotipagem de alta resolução. Métodos de tipagem para análise de genoma total como o PFGE, AFLP e RFLP, são tradicionalmente mais discriminatórios do que os métodos desenvolvidos para a análise de sequências específicas como a ribotipagem e o PCR-RFLP. Cabe ressaltar que os resultados obtidos a partir da análise de genoma total permitem a comparação entre isolados distintos, enquanto a análise de regiões específicas, se limita a detectar possíveis variações presentes nessas sequencias em estudo. O poder discriminatório também é influenciado por condições experimentais como a escolha da enzima, dos iniciadores (primers) e ajustes de ciclagem. O elevado poder discriminatório, atribuído a alguns métodos, não é uma condição universal e pode variar conforme o grupo microbiano em estudo. A reprodutibilidade deve também ser considerada como um critério importante para os ensaios realizados dentro e entre laboratórios de modo a subsidiar o monitoramento de agentes infecciosas. Além da reprodutibilidade, a estabilidade também é um importante critério a ser considerado na escolha do método a ser usado. Outras considerações importantes incluem a disponibilidade de equipamentos, o custo dos reagentes, a adequação física, a qualificação técnica e o tempo necessário para a execução do procedimento até a obtenção de resultados (GWINN, BOWEN, KHOURY, 2006; MacCANNELL, 2013; RANJBAR et al., 2014; TAUXE, 2006). O sequenciamento de DNA requer um sequenciador que é um equipamento de elevado custo, mas altamente discriminatório; alguns métodos baseados em análise do padrão de bandas como o PFGE requer equipamento especial, mas é considerado método referência para a tipagem de relevantes patógenos bacterianos. Muitos métodos utilizam sistema de eletroforese que opera sob refrigeração. Metodologias baseadas em ensaios de amplificação são bastante acessíveis e utilizam termocicladores. Para a execução da técnica do PCR convencional o custo pode ser mais acessível. A amplificação em tempo real é uma variante metodológica mais custosa por requerer equipamento mais robusto acoplado a sistema automatizado. Os programas utilizados para capturar e analisar as imagens dos padrões de bandas (polimorfismo) e de curvas de melting são oferecidos no mercado e os preços variam conforme os recursos técnicos disponibilizados.

Os sistemas de tipagem constituem importantes ferramentas laboratoriais para estudos de vigilância, uma vez que permitem detectar a inter-relação genética de microrganismos e de sequencias específicas, e, consequentemente, possibilita identificar a circulação de padrões genéticos que caracterizam o perfil epidemiológico de um dado agente infeccioso.

\section{Conclusão}

$\mathrm{Na}$ era genômica, a genotipagem tem se beneficiado cada vez mais da bioinformática que é uma ferramenta de análise de extrema relevância para a detecção de um dado agente infeccioso e de suas variantes. Esses resultados podem ser comparados entre diferentes laboratórios possibilitando estudos retrospectivos e de vigilância epidemiológica realizados 
por longos períodos. Métodos de tipagem desenvolvidos para o estudo de regiões ou sequências específicas de DNA têm sido atualmente direcionados para a análise de muitos loci e a análise de genoma total tem permitido identificar os aspectos da diversidade. Os resultados provenientes dessas análises têm grande aplicabilidade no manejo do tratamento e na elucidação do padrão epidemiológico das doenças infecciosas.

Os diversos métodos de tipagem apresentam vantagens e desvantagens. Consequentemente, a escolha de um método de genotipagem adequado não é simples e vai depender do objetivo do estudo, da disponibilidade de equipamentos e de outras variáveis técnica-operacionais como o poder de tipagem, a reprodutibilidade, a resolução, o custo, a facilidade de execução e o tempo para se obterem os resultados. A decisão sobre o uso de métodos de tipagem alternativos ou complementares deve sempre considerar a análise conjunta da genotipagem aliada aos dados clínicos e ao contexto epidemiológico.

\section{REFERÊNCIAS BIBLIOGRÁFICAS}

1. BARRETO, M.L. et al. Sucessos e fracassos no controle de doenças infecciosas no Brasil: o contexto social e ambiental, políticas, intervenções e necessidades de pesquisa. Lancet Brasil, Saúde no Brasil, v.3, p. 47-60, 2011.

2. BELKUM, A.V.et al. Role of Genomic Typing in Taxonomy, Evolutionary Genetics, and Microbial Epidemiology. Clinical Microbiological Review, v.4, p. 547$560,2001$.

3. BLANC, D.S. The use of molecular typing for epidemiological surveillance and investigation of endemic nosocomial infections. Infection, Genetics and Evolution, v.4, p. 193-197, 2004.

4. GILBERT, G.L. Molecular diagnostics in infectious diseases and public health microbiology: cottage industry to postgenomics. Trends in Molecular Medicine, v.8, p. 280-287, 2002.

5. GWINN, M., BOWEN, M., KHOURY, M. Genomics and Public Health at CDC. Morbidity and Mortality Weekly Report, v. 55, p. 20-21. 2006.

6. HASNAIN, S.E. Molecular epidemiology of infectious diseases: a case for increased surveillance. Bulletin of the World Health Organization, v.81, n.7, 2003.

7. LI, W., RAOULT, D., FOURNIER, P.-E. Bacterial strain typing in the genomic era. FEMS Microbiology Reviews, v.33, p. 892-916, 2009.

8. MacCANNELL, D. Bacterial Strain Typing. Clinics in Laboratory Medicine, v.33, p. 33: 629-650, 2013.

9. MILLAR, B.C., XU J., MOORE, J.E. Molecular Diagnostics of Medically Important Bacterial Infections. Current Issues in Molecular Biology, v.9, p. 21-40, 2007.

10. RANJBAR, R. et al. Typing methods used in the molecular epidemiology of microbial pathogens: a how-to guide. New Microbiologica, v.37, p.1-15, 2014.

11. SINGH, A. et al. Application of Molecular Techniques to the Study of Hospital Infection. Clinical Microbiology Reviews, v. 19, p. 512-530, 2006.

12. SINTCHENKO, V., GALLEGO, B. Laboratory-Guided Detection of Disease Outbreaks Three Generations of Surveillance Systems. Archives of Pathology \& Laboratory Medicine, v.133, p. 916-925, 2009.

13. SINTCHENKO, V., IREDELL, J.R., GILBERT, G.L. Pathogen profiling for disease management and surveillance. Nature Reviews, v.5, p. 464-470, 2007. 
14. LUKINMAA, S. et al. Application of molecular genetic methods in diagnostics and epidemiology of food-borne bacterial pathogens. Acta Pathologica, Microbiologica, et Immunologica,v.112, p.908-29, 2004.

15. SWAMINATHAN, B. et al. PulseNet: The Molecular Subtyping Network for Foodborne Bacterial Disease Surveillance, United States. Emerging Infectious Diseases, v.7, p. 382- 389, 2001.

16. TAUXE, R.V. Molecular Subtyping and the Transformation of Public Health Foodborne Pathogens and Disease, v. 3, p. 4-8, 2006. 